\title{
Functional Diagnostics of Soil Fertility Elements
}

ISSN: 2637-7659

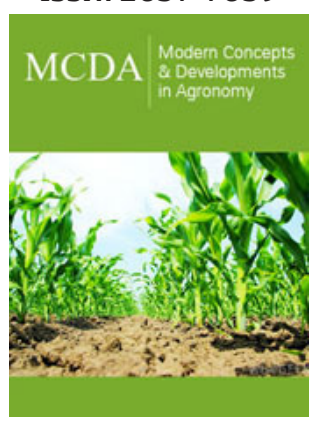

*Corresponding author: Roman Truskavetskyi, Doctor of Agricultural Sciences, National Scientific Center, Institute for Soil Science and Agrochemistry Research named after O.N. Sokolovsky, Kharkov, Ukraine

Submission: 1-i-n August 07, 2020

Published: 䟧August 27, 2020

Volume 7 - Issue 1

How to cite this article: Roman Truskavetskyi. Functional Diagnostics of Soil Fertility Elements. Mod Concep Dev Agrono. 7(1). MCDA. 000655. 2020. DOI: 10.31031/MCDA.2020.07.000655

Copyright@ Roman Truskavetskyi, This article is distributed under the terms of the Creative Commons Attribution 4.0 International License, which permits unrestricted use and redistribution provided that the original author and source are credited.

\section{Roman Truskavetskyi*}

Doctor of Agricultural Sciences, National Scientific Center, Institute for Soil Science and Agrochemistry Research named after O.N. Sokolovsky, Kharkov, Ukraine

\section{Opinion}

The concentration (activity) of mineral nutrients in soil solution of soils with different genetic structure and state of cultivation is constantly changing during the ontogenetic development of plants. The dynamics of this change is due not only to external factors, but also to internal soil buffer mechanisms, which significant diagnostic role is still ignored. Therefore, additional diagnostic criteria are needed that would take into account the dynamics of concentration (activity) of the most accessible for plants biogenic elements ("intensity factor"-IF), as well as soil ability to refound plants the most available biogenic elements. Functional diagnostics of soil fertility elements, as the main scientific course of our long-term fundamental research, is carried out on the basis of modeling the processes of soil internal regulation of soil solution, which is determined by soil buffer ability. As is commonly known, many different methods for diagnosing soil trophic regimes have been developed and recommended, which are expected to determine different forms of biogenic elements in soil environment-from highly mobile to variously connected with the solid "phase" of soil ones [1].

However, a close correlation is absent, as a rule, between both the content of mobile forms of biogenic elements in soils of different genesis and yields. It is due not only to the well-known processes of antagonism-synergism between nutrients for the right to enter the biological cycle, but also to autoregulation processes-natural and acquired ability of soils to hold and maintain at a quasi-equilibrium level the genetically inherent value of IF [2]. Currently, knowledge of soil ability to buffer external influences remains too stingy. "Buffer" issues in agricultural soil science, except for acid-base buffer ability (pH-buffering), are poorly studied. "Buffer" criterion, including pH-buffering, is usually not used in fertility management system. At the same time, the importance of this criterion cannot be doubted in the improving the class of soil monitoring and the effectiveness of soil regime management. Fertility optimization (Latin "optimum"-the best) should be interpreted as a process of transferring the fertility elements from unsatisfactory state to its optimum and creating conditions (mainly by amelioration measures) for their sustainable maintenance in this state. Whereas the state of soil fertility is constantly and dynamically changing, which depends on weather conditions and agricultural culture, the choice of effective criteria for its optimization is impossible without the functional diagnostics, which takes into account the dynamics of content and reserves of fertility element in soil solution. The latter one is too dynamic and at the same time the most influential factor in yield formation. The composition of soil solution is constantly changing and incurs the most evident oscillations under the influence of moisture and interaction with solid, living and gaseous "phases" of soil. Anisotropy and high inertia are specific to high humus clay soils. Just those soils are characterized, as a rule, by high immobilization buffer capacity relatively to the vast majority of fertility elements $[3,4]$. On the contrary, the tendency to fluctuation of the soil solution is inherent in soils with low buffer capacity and poor bio-organo-mineral complex. As it is known, soil solution is the most dynamic part of the soils and it is a direct source of water and mineral nutrition of plants. 
Main goal of functional diagnostics and precession agriculture is to maintain constantly soil solution in the optimal agroecological condition during the plant vegetation. The cycle of biogenic elements starts from the soil solution. The concentration and content of biogenic elements in soil solution change over the course of soil formation under the influence of such factors as weathering of minerals, destruction-synthesis of organic compounds, migration and accumulation, emission and fixation of nitrogen and carbon gases, human activity, changes in weather conditions etc. In laboratory-analytical practice, soil solution is studied by simulating it, first of all, with water, neutral-salt extracts from soil, as well as with soil pastes, suspensions, centrifuges, followed by further determination of their agrochemical quality. The closest to the natural state are extragents of soft "action" on the soil-water and neutral-salt, which do not destructively affect the solid phase of soil and thus do not cause significant changes in the chemical composition of soil solution. At the same time, neutral-salt and water soil extracts do not give a complete answer about the level of soil supply with biogenic elements, which mostly are in a passiveaccessible state for plants ("capacity factor"-CF) [5]. This factor is determined by more aggressive extragents-acids and alkalies. However, these methods do not fully assess the actual agroecological condition of the soil solution, and, furthermore, its chemical composition is disturbed due to the destructive (aggressive) action of acids and alkalies on the soil substrate.

Therefore, it makes no sense to use methods of "hard" chemical diagnostics to optimize soil fertility. However, acidic and alkaline extracts from soil make it possible to estimate the "capacity factor" (CF) of the fertility element as the closest reserve for the refounding of IF deficiency-plants the most mobile and accessible form of biogenic element in soil. These two factors (CF and IF) are in a thermodynamic quasi-equilibrium, which is different depending on the buffer properties of soil. Assessment of the agroecological quality of soil solution is also significantly complicated by the processes of biogenic elements interaction with each other for the right to be included in the biological cycle. In some cases, such processes inhibit (antagonism), and in others-contribute to the absorption of biogenic elements by plant root system (synergism). In agricultural and agrochemical practices of Ukraine, the level of soil biogenic elements supply is mostly determined with acid and alkaline soil extracts. However, these methods are imperfect and received data cannot be used as criteria for calculating the standards of nutrient optimization. Capacity factor (CF) represents only that part of the reserves of biogenic element that is in a bound (deposited) state and is able (under certain conditions) to pass into the soil solution, compensating for the deficiency of "intensity factor" (IF). Soil ability, which partially compensates and balances the content of a biogenic element in soil solution during plant nutrition, is defined as its buffer capacity. Concentration (activity) of biogenic elements in soil solution can be low, but optimal functioning of soil buffer mechanisms creates favorable conditions for normal mineral nutrition of plants than for high, but unstable and rapidly depleting, IF, which occurs in soils with too low or excessively high buffer capacity. Thus, the state of instability of mineral nutrition of plants is caused not only by the appearance of a deficiency of IF in soil solution, and by providing soil ability to compensate for this deficiency at the expense of CF. Graphic models of functional diagnostics and optimization of soil fertility are highlighted in our monograph "Buffer ability of soils and their main functions" [6], as well as in a number of published scientific articles, to which I can address with great pleasure and in advance each interested researcher and reader.

\section{References}

1. Truskavetskyi RS, Tsapko Yu L, Tcheshko NF (2006) Soil buffer mechanisms: significance, meaning and prospects of the research. Bulletin of Agrarian Science 6: 27-33.

2. Truskavetskyi RS (2009) Role of the autoregulation processes in the diagnostics of soil trophic regimes. Bulletin of Agrarian Science 4: 17-20.

3. Truskavetskyi RS (2014) Amelioration as a method for the reconstruction of nature and developing of new soil buffer mechanisms. Materials of the $9^{\text {th }}$ congress of UTGA. Mykolayiv, Ukraine, p. 4.

4. Truskavetskyi RS, Tsapko Yu L (2016) Fundamentals of soil fertility management / Monograph. In: Truskavetskyi RS (Ed.), Kharkov, Ukraine, p. 385.

5. (2018) Models of soil fertility system management (on the example of Kharkov and Volin regions). USAID, Research and practice edition, Balyuk SA, Truskavetskyi RS (Eds.), Kiev-Kharkov, Ukraine, p. 116.

6. Truskavetskyi RS (2003) Buffer ability of soils and their main functions. Kharkov, Ukraine, p. 225.

For possible submissions Click below:

Submit Article 